\title{
Revistas de Pediatría del Cono Sur: un camino de integración
}

\author{
FRANCISCA UGARTE P. ${ }^{1}$, LUISA SCHONHAUT B. ${ }^{1}$, \\ PAUL HARRIS D. ${ }^{1}$, FRANCISCO CANO SCH. ${ }^{1}$
}

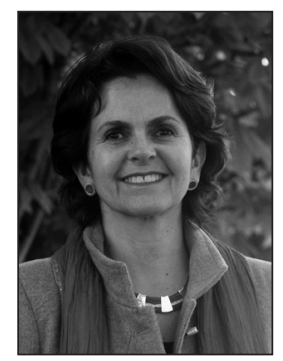

1. Comité Editorial Revista Chilena de Pediatría.

La Revista Chilena de Pediatría se integró al grupo de Editores de Revistas de Pediatría de las Sociedades de Pediatría del Cono Sur el año 1999, con el fin de profundizar el mutuo conocimiento de las publicaciones de los países participantes (Argentina, Bolivia, Brasil, Chile, Paraguay y Uruguay), establecer una red en Latinoamérica que permitiera a nuestra publicación una mayor visibilidad y compartir iniciativas destinadas a mejorar la calidad de nuestras revistas, de tal manera de acceder a índices internacionales que permitieran que el esfuerzo de investigadores, autores y editores de la región, contribuyeran al conocimiento y desarrollo de la Pediatría, no solo del propio país, sino también de otras regiones de un mundo cada vez más globalizado.

Han pasado ya 14 años y la situación inicial ha cambiado radicalmente: todas las revistas de las Sociedades participantes se encuentran indexadas en SciELO (como sitios activos o en desarrollo), y dos de ellas (Jornal de Pediatría de Brasil y Archivos Argentinos de Pediatría) ya indexados en PubMed.

Los pasos que las revistas de la región han dado para alcanzar sus estados actuales son múltiples: adoptamos las normas internacionales de publicación de la WAME (World Assocciation of Medical Editors), perfeccionamos los procesos editoriales incorporando sistemas digitales, revisión por pares y por asesores téc- nicos, logrando regularidad en la publicación, cumpliendo requisitos bioéticos y de conflicto de intereses, etc. así como optimizando la calidad de impresión (gráfica, papel, edición, etc.).

Revista Chilena de Pediatría no ha estado ajena a este proceso: su incorporación a SciELO el año 1998 y la subida de la colección completa el 2007, teniendo actualmente 430 números en el portal; el cambio de formato y portada el año 2007, los cambios en la calidad del papel y formato de página para facilitar su lectura; la implementación de la plataforma OJS (Open Journal System) para un proceso editorial on-line el 2010, y la incorporación de código QR con disponibilidad de la revista a texto completo para tablets y acceso a artículos venideros ("forthcoming articles") en 2012; las recientes modificaciones de la estructura del Comité Editorial con incorporación de Editores de Sección y un gran equipo colaborador detrás de cada uno de ellos; la incorporación de miembros de regiones, de asesores de idioma y estadística, han sido parte de las múltiples iniciativas implementadas a nivel local, y que han permitido recibir un flujo cada vez mayor de artículos tanto de Chile como del extranjero.

El impacto de las medidas antes señaladas ha determinado un mayor interés por publicar en Revista Chilena de Pediatría y una mayor visibilidad de la Revista no sólo en Chile, sino también en la región y en países de habla his- 
pana. Los indicadores bibliométricos proporcionados por SciELO en 2012 indican que Revista Chilena de Pediatría recibió 12.688 visitas a su página de ingreso y 1.423 .795 visitas a artículos; en lo que va del 2013 (4 números) 21.917 visitas a la página y 1.818 .649 a artículos. La visibilidad de nuestra revista, ha hecho que más autores envíen sus artículos a revista chilena de Pediatría, es así como en 2012 recibimos 125 manuscritos para su consideración, se publicaron un total de 79 , de los cuales 6 artículos provenían del extranjero. Este año hemos recibido 97 artículos a la fecha y ya hemos publicado 60 artículos, 5 provenientes del extranjero.

La necesidad de ir adecuando la Revista Chilena de Pediatría a la importante producción científica nacional ha sido uno de los estímulos más importantes en la modernización de este órgano editorial. La producción científica en Chile puede ser visualizada a través de los datos del RICYT 2010 (Red de Indicadores de Ciencia y Tecnología Iberoamericana), donde podemos observar que el número de publicaciones SCI ajustada por 100.000 habs para Chile, Argentina y Brasil, es de 30,2, 21,2 y 18,7 artículos $/ 10^{5}$ habitantes. En Iberoamérica, España y Portugal muestran 159 y 102 artículos $/ 10^{5}$ habs respectivamente. El porcentaje de inversión en Investigación y Desarrollo de la región respecto al PBI (Producto Interno Bruto), aún aparece lejos de las cifras del mundo desarrollado, sin embargo, al mirar el número de publicaciones SCI ajustadas por PBI, Chile muestra una cifra de 25.39 , en comparación a Argentina y Brasil con 22,8 y 16,8 respectivamente. Por otra parte, nuevamente España y Portugal muestran cifras superiores a las locales, con un 36,8 y 47,3 respectivamente.

Recientemente se realizó en Mar del Plata, Argentina, la XII Reunión de Editores de revistas de las Sociedades de Pediatría del Cono Sur, en el marco del $36^{\circ}$ Congreso Argentino de Pediatría. Asistieron representantes de todas las revistas del grupo y en ella cada uno dio a conocer la situación actual de su revista y las principales novedades relacionadas al quehacer editorial. De estas, cabe destacar que a la decisión tomada hace algunos años por el Jornal de Pediatría de publicar la revista en in- glés y mantener sólo un número reducido de volúmenes en portugués, se agregó la de no publicar más la versión escrita (dejando sólo la versión electrónica) y la de haberse incorporado a Elsevier con el traspaso del proceso de edición, traducción, impresión y distribución, manteniendo todo el proceso de dirección y selección de artículos en manos del equipo editorial, y continuar con el acceso abierto al Jornal (Full Text Open Access). Archivos Argentinos de Pediatría ha incorporado la publicación de todos sus artículos originales, editoriales y comunicaciones breves en idioma inglés en la versión electrónica. Por su parte, Paraguay agregó la publicación en colores de figuras y títulos, y al igual que Bolivia y Uruguay, continúan desarrollando su portal en Scielo.

Chile llevó a la reunión una innovadora iniciativa, la propuesta de una nueva plataforma digital de árbitros, desarrollada gracias al apoyo de la Sociedad Chilena de Pediatría. Esta plataforma permite la colaboración arbitral entre los países de la región. La principal ventaja que ofrece una plataforma común de árbitros, es disponer de un mayor grupo de árbitros especialistas, la posibilidad de recurrir a ella en caso de conflicto de intereses o ausencia de revisores especialistas en el país. Esta sería la primera iniciativa de colaboración editorial propiamente tal y fue ampliamente apoyada por los países participantes. De aprobarse por los respectivos directorios de las revistas, se implementaría durante el presente año.

A la luz de las tendencias actuales en publicación biomédica, nos queda mucho por hacer: debemos definir si migraremos o no a una publicación principal o exclusivamente digital (lo que conlleva disminución de los costos de producción de la revista y un aporte a la conservación del medio ambiente); si incorporaremos el idioma inglés para algunos de los artículos de nuestra revista (aumentando así la llegada a lectores de habla inglesa) y definir la implementación de otras estrategias que permitan una mayor visibilidad aún. En este sentido la incorporación de nuevas herramientas informáticas y bibliométricas al proceso editorial, nos permitirán conocer con mayor certeza las necesidades de nuestros lectores, el impacto de las distintas medidas tomadas y así orien- 
tar nuevas iniciativas para el mejor desarrollo de Revista Chilena de Pediatría.

Las actividades del Grupo de Editores de Revistas de las Sociedades de Pediatría del Cono Sur, han sido un buen ejemplo de cola- boración regional y sus frutos han quedado a la vista. Iniciativas similares debieran enriquecer el quehacer de nuestras Sociedades y dar una mayor relevancia a la Pediatría de nuestra región, en el contexto mundial. 